\title{
NK4 regulates 5-fluorouracil sensitivity in cholangiocarcinoma cells by modulating the intrinsic apoptosis pathway
}

\author{
XIANXIU GE ${ }^{1}$, YOULI WANG ${ }^{2}$, QUANPENG LI $^{1}$, HONG YU ${ }^{1}$, GUOZHONG JI ${ }^{1}$ and LIN MIAO ${ }^{1}$ \\ ${ }^{1}$ Institute of Digestive Endoscopy and Medical Center for Digestive Diseases, \\ Second Affiliated Hospital of Nanjing Medical University, Nanjing, Jiangsu 210011; ${ }^{2}$ The Clinical Laboratory of \\ Nanjing Hospital Affiliated to Nanjing Medical University, Nanjing, Jiangsu, P.R. China
}

Received January 31, 2013; Accepted March 4, 2013

DOI: $10.3892 /$ or.2013.2427

\begin{abstract}
The aim of the present study was to investigate the role of $\mathrm{NK} 4$, an antagonist for hepatocyte growth factor (HGF) and the Met receptor, in regulating the response of cholangiocarcinoma (CCA) cells to 5-fluorouracil (5-FU). We established the CCA cell line, HuCC-T1, to produce abundant NK4 (Hu-NK4). Cell proliferation, cell cycle distribution, apoptosis, 5-FU metabolism and intracellular signaling were examined. There were no significant differences in the mRNA levels of thymidylate synthase, thymidine phosphorylase and dihydropyrimidine dehydrogenase between the mock-transfected control $\mathrm{Hu}-\mathrm{Em}$ cells and $\mathrm{Hu}-\mathrm{NK} 4$ cells, suggesting that NK4 expression does not alter 5-FU metabolism. Moreover, cell cycle analysis showed that 5 -FU treatment caused a decrease in the proportion of cells in the G2/M phase while NK4 gene expression had little effect on the cell cycle distribution. However, 5-FU-induced apoptosis was significantly increased in the Hu-NK4 cells when compared to that in the $\mathrm{Hu}-\mathrm{Em}$ cells. Further investigation revealed that NK4 gene expression enhanced 5-FU-induced caspase-3 and caspase-9 activation, and that the apoptosis of cells was associated with modulation of expression of the Bcl-2 family members. Furthermore, western blot analysis revealed that both NK4 and 5-FU were inhibitors for HGF-induced phosphorylation of Met, but they may be independent factors. Collectively, these results suggest that following 5-FU treatment in CCA cell lines, NK4 was involved in apoptosis induction through the intrinsic mitochondrial pathway. This indicates that NK4 may be an important mediator of 5-FU-induced cell death. Moreover, downregulation of NK4 in response to 5-FU may represent an intrinsic mechanism of resistance to this anticancer drug.
\end{abstract}

Correspondence to: Professor Lin Miao, Institute of Digestive Endoscopy and Medical Center for Digestive Diseases, Second Affiliated Hospital of Nanjing Medical University, 121 Jiang Jia Yuan, Xiaguan, Nanjing, Jiangsu 210011, P.R. China

E-mail: miaofrest@yahoo.com.cn

Key words: NK4, 5-fluorouracil, chemoresistance, apoptosis, cholangiocarcinoma

\section{Introduction}

Cholangiocarcinoma (CCA) is an incurable and lethal cancer which arises from the epithelial cells of the bile ducts. Early diagnosis, with potential surgical intervention, has been the exception rather than the rule with only $30 \%$ of patients qualifying for attempted surgical cure (1). Despite advances, the median survival is $<24$ months (2). 5-Fluorouracil (5-FU), an antimetabolite, is currently the standard treatment for CCA. Although 5-FU yields great clinical benefit in patients with advanced CCA, the response rates of $\sim 10-40 \%$ and the survival benefits when 5-FU is used alone are very low (3). The prognosis for the majority of patients with advanced CCA remains poor due to intrinsic or acquired chemoresistance. Therefore, identification of the signaling molecules involved in mediating the response of CCA to 5-FU is required to determine the underlying mechanisms of 5-FU resistance.

A common cause of treatment failure in CCA is chemoresistance, which may be related to the redox state of cancer cells and the tumor microenvironment, where growth factors play important roles. Hepatocyte growth factor (HGF) was originally identified as a mitogenic protein for hepatocytes, and it can promote CCA cell invasiveness through dyslocalization of E-cadherin and induction of cell motility by distinct signaling pathways $(4,5)$. Met, which is overexpressed in the tissues of CCA patients, is known to be the only specific receptor for HGF. NK4 is a fragment of HGF, consisting of the N-terminal (N) and four kringle domains (K4) of HGF. It competitively inhibits HGF binding to Met and inhibits the phosphorylation of Met tyrosine kinase. It was the first-identified specific inhibitor for the HGF/Met pathway (5).

The HGF/Met pathway has become a hot target in anticancer drug development $(6,7)$. Activation of the HGF/Met pathway in cancer cells contributes to resistance to chemical and physical treatment of cancer $(8,9)$. Recent studies revealed that activation of the HGF/Met pathway is a novel mechanism by which non-small cell lung cancers become resistant to EGFR inhibitors (10). It has been reported that combined treatment with an adenoviral vector expressing NK4 (Ad-NK4) with gemcitabine may be a promising approach for treating pancreatic cancer, and that this combination therapy may decrease the risks of side effects (11). In addition, NK4 gene therapy combined with cisplatin inhibits tumor growth and 
the metastasis of squamous cell carcinoma (11). Murine colon cancer CT26 cells expressing NK4 demonstrated enhanced 5-FU-induced cell apoptosis via downregulation of intracellular signaling of the HGF/Met pathway (12). In brief, NK4 is a potential regulator of chemotherapy resistance in many types of malignances. Therefore, treatment with NK4 may offer a new therapeutic option for the inhibition of chemoresistance and better outcomes for cancer patients.

A review summarized the epigenetic mechanisms triggering resistance to three commonly used agents in colorectal cancer, including 5-FU (13). Studies undertaken to determine the molecular mechanisms of intrinsic and acquired resistance to 5-FU have found various alterations of drug target(s) and metabolism $(14,15)$, such as key enzymes of 5-FU anabolism and catabolism including thymidylate synthase (TS) (16), thymidine phosphorylase (TP) (17) and dihydropyrimidine dehydrogenase (DPD). It had been confirmed in tissue and from mRNA levels that negative DPD (not TS) expression is significantly associated with the enhanced tumor cell proliferation and poorer prognosis in patients with intrahepatic cholangiocarcinoma $(18,19)$. In addition, altered expression of apoptosis-regulating genes also can lead to resistance to 5-FU (20). Since research is limited concerning the combination of NK4 gene therapy and 5-FU chemotherapy in CCA, the aim of this study was to investigate the mechanism by which NK4 regulates the 5-FU response in HuCC-T1 cells.

\section{Materials and methods}

Reagents. Antibodies against Met, Bcl-2 and Bax were obtained from Santa Cruz Biotechnology (Santa Cruz, CA, USA). Rabbit monoclonal antibodies against phospho-Met (Tyr1003) were obtained from Cell Signaling Technology (Danvers, MA, USA). Antibodies against $\beta$-actin and antigoat/rabbit immunoglobulin $\mathrm{G}$ ( $\mathrm{IgG}$ )-horseradish peroxidase (HRP) were obtained from BioWorld (Atlanta, GA, USA). 5-FU and cisplatin were obtained from Qilu Pharmaceutical Co., Ltd. (Shandong, China), and doxorubicin was from Nanjing KeyGen Biotech., Co., Ltd. (Nanjing, China). All the other chemicals used were of analytical reagent grade.

Cell cultures. HuCC-T1 human cholangiocarcinoma cells (ATCC, Manassas, VA, USA) were cultured in Dulbecco's modified Eagle's medium (DMEM; Gibco Laboratories, Grand Island, NY, USA) supplemented with $10 \%$ fetal bovine serum (FBS; Gibco, Carlsbad, CA, USA) in $5 \% \mathrm{CO}_{2}$ at $37^{\circ} \mathrm{C}$ until reaching a confluence range of $50-60 \%$. Then the human NK4 expression plasmid pcDNA3/NK4 (provided by Professor Toshikazu Nakamura, Osaka University, Japan) was transfected into HuCC-T1 using X-tremeGENE HP (Roche Molecular Biochemicals, Indianapolis, IN, USA). After $48 \mathrm{~h}$, the cells were cultured in selective medium containing $900 \mu \mathrm{g} / \mathrm{ml} \mathrm{G} 418$ (Sigma, St. Louis, MO, USA) for the selection of resistant colonies. The expression of NK4 protein was assessed by western blotting. A transfectant expressing a high level of NK4 was designated as Hu-NK4. Cells transfected with empty vector pcDNA3 alone were designated as $\mathrm{Hu}-\mathrm{Em}$ and used as the control.

Cell growth assay. $\mathrm{Hu}-\mathrm{Em}$ and $\mathrm{Hu}-\mathrm{NK} 4$ cells were cultured in 96-well plates at a density of $5 \times 10^{3}$ cells/well overnight, and then treated with 5-FU $(0,0.1,1,10$ and $100 \mu \mathrm{M})$, cisplatin $(0,0.01,0.1,1$ and $10 \mu \mathrm{M})$ or doxorubicin $(0,0.01,0.1,1$ and $10 \mu \mathrm{M})$. Cells were cultured for 48 and $72 \mathrm{~h}$. During the last $4 \mathrm{~h}, 3$-(4,5-dimethylthiazol-2-yl)-2,5-diphenyltetrazolium bromide (MTT) (Sigma) was added to a final concentration of $1 \mathrm{mmol} / \mathrm{l}$. The formazan product was dissolved in dimethyl sulfoxide $(150 \mu \mathrm{l})$, and the absorbances were read on a microplate reader (Bio-Rad Laboratories, Hercules, CA, USA) at $490 \mathrm{~nm}$. Each result was corrected by values from a control study. Experiments were performed in triplicate and repeated at least three times.

Real-time reverse transcription $(R T)-P C R$. Total RNA was isolated from cells using the TRIzol total RNA isolation kit (Invitrogen) according to the manufacturer's protocol. RNA was eluted with RNase-free water. RT-PCR was performed using the Transcriptor First Strand cDNA Synthesis kit (Roche Molecular Biochemicals) according to the manufacturer's protocol. Briefly, reactions were incubated at $65^{\circ} \mathrm{C}$ for $10 \mathrm{~min}$, at $55^{\circ} \mathrm{C}$ for $30 \mathrm{~min}$, and then at $85^{\circ} \mathrm{C}$ for $5 \mathrm{~min}$. Oligonucleotide primers (TYMS forward, 5'-CCTGCTCACGTACATGAT TGC-3' and reverse 5'-TTT GGGAAAGGTCTGGGTTC-3'; TYMP forward, 5'-GCTGCTGTATCGTGGGTCA-3' and reverse, 5'-GAGAATGGAGGCTGTGATGAG-3'; DPYD forward, 5'-CAATGAGATGCCTGAAATGTG-3' and reverse, 5'-AAGTCAGACCAAGTGGGTTGT-3'; $\beta$-actin forward, 5'-TCACCCACACTGTGCCCATCTACGA-3' and reverse, 5'-CAGCGGAACCGCTCATTGCCAATGG-3') were designed using Primer 5 software, and synthesized by Invitrogen. Real-time monitoring of PCR products was carried out using the SYBR-Green Master Mix (Roche Molecular Biochemicals) and the Prism 7500 Real-Time PCR Detection system (Applied Biosystems, Foster City, CA, USA). Cycling conditions were $95^{\circ} \mathrm{C}$ for $10 \mathrm{~min}$, followed by 40 repeats of $95^{\circ} \mathrm{C}$ for $15 \mathrm{sec}$ and $60^{\circ} \mathrm{C}$ for $1 \mathrm{~min}$. Levels of mRNAs were calculated using the comparative cycle threshold $(\Delta \Delta \mathrm{CT})$ method and normalized to $\beta$-actin, the internal control, to obtain the relative mRNA level of each target.

Flow cytometry for cell cycle analysis and measurement of apoptosis. $\mathrm{Hu}-\mathrm{Em}$ and $\mathrm{Hu}-\mathrm{NK} 4$ cells were seeded in a 6-well plate at a density of $1 \times 10^{5}$ cells/well and incubated overnight. Cells were treated with $0,1,10$ and $100 \mu \mathrm{M} 5-\mathrm{FU}$ for $48 \mathrm{~h}$, then harvested by trypsinization, fixed in ice-cold $70 \%$ ethanol at $4^{\circ} \mathrm{C}$ overnight. Cells were washed, suspended in $1 \mathrm{ml}$ propidium iodide (PI) staining solution $(50 \mu \mathrm{g} / \mathrm{ml} \mathrm{PI}, 30 \mathrm{U} / \mathrm{ml}$ RNase A, $0.1 \%$ Triton $\mathrm{X}-100,4 \mathrm{mM}$ sodium citrate) and incubated at $37^{\circ} \mathrm{C}$ for $10 \mathrm{~min}$. Typically, 10,000 gated events were collected on a FACScan machine (Beckton-Dickinson, Franklin Lakes, NJ, USA) and analyzed by CellQuest software (BecktonDickinson). Cell cycle analysis was carried out using FlowJo software (Tree Star, San Carlos, CA, USA). Apoptotic cells were measured by flow cytometry using the FITC Annexin V Apoptosis Detection Kit I (BD Biosciences, San Diego, CA, USA) according to the manufacturer's instructions.

Assays of caspase-3 and caspase-9 activity. Hu-Em and $\mathrm{Hu}-\mathrm{NK} 4$ cells were cultured in 6-well plates overnight, and then treated with $0,1,10$ and $100 \mu \mathrm{M}$ 5-FU. After treatment with 5-FU for $48 \mathrm{~h}$, caspase-3 and -9 activity was assayed using 
the Caspase Colorimetric Assay kit (Nanjing KeyGen Biotech) according to the manufacturer's protocol. Briefly, the cells were lysed in a lysis buffer for $30 \mathrm{~min}$ in an ice bath. The lysed cells were centrifuged at $12,000 \mathrm{xg}$ for $10 \mathrm{~min}$, and $200 \mu \mathrm{g}$ of the protein was incubated with $50 \mu \mathrm{l}$ of a reaction buffer and $5 \mu \mathrm{l}$ of the substrate for caspase-3 and caspase-9, respectively, at $37^{\circ} \mathrm{C}$ for $4 \mathrm{~h}$. The optical density of the reaction mixture was quantified spectrophotometrically at a wavelength of $405 \mathrm{~nm}$. The assay was repeated three times and similar results were obtained.

Western blot analysis. For Bcl-2 and Bax detection, Hu-Em and $\mathrm{Hu}-\mathrm{NK} 4$ cells were serum-starved for $12 \mathrm{~h}$ and then incubated with $0,1,10$ and $100 \mu \mathrm{M} \mathrm{5-FU}$ for $48 \mathrm{~h}$ and total proteins were extracted. For Met detection, 5-FU and HGF were added to cells, respectively, or their combination, in which $10 \mu \mathrm{M}$ 5-FU was incubated with Hu-Em and Hu-NK4 cells for $48 \mathrm{~h}$, and then $20 \mathrm{ng} / \mathrm{ml}$ HGF was added to the cells $1 \mathrm{~h}$ before harvested. Then protein extracts were run on a $7 \%$ polyacrylamide gel and were transferred onto polyvinylidene difluoride (PVDF) membranes (Millipore, Billerica, MA, USA). Non-specific binding was blocked by incubation of the membranes with $5 \%$ non-fat milk for $2 \mathrm{~h}$, followed by incubation with the primary antibody at $4{ }^{\circ} \mathrm{C}$ overnight. The membrane was then washed with TBST for $15 \mathrm{~min}$. This step was repeated four times. After being washed, the membrane was incubated with HRP-conjugated secondary antibodies for $1 \mathrm{~h}$ at room temperature, washed with TBST for $10 \mathrm{~min}$ and repeated four times, and visualized by an enhanced chemiluminescence kit (Amersham, Piscataway, NJ, USA).

Statistical analysis. Data are presented as the means \pm SE. Statistical analysis was carried out using the independentsamples t-test or one-way ANOVA, with $\mathrm{P}<0.05$ considered to indicate a statistically significant difference.

\section{Results}

NK4 overexpression increases the sensitivity of $\mathrm{HuCC}-\mathrm{Tl}$ cells to 5-FU. To select the best partner for NK4 gene therapy from among conventional chemotherapeutic agents, we examined the effect of 5-FU, cisplatin and doxorubicin on the in vitro proliferation of NK4-expressing HuCC-T1 cells by MTT assay. There was little difference in cell proliferation between the Hu-Em and Hu-NK4 cells under conditions without drugs. All drugs reduced the cell proliferation of both transfectants in a dose-dependent manner. 5-FU, in particular, dose-dependently reduced the cell proliferation of Hu-NK4 cells to a greater extent when compared to that of $\mathrm{Hu}-\mathrm{Em}$ cells and to a greater exent than did cisplatin and doxorubicin (Fig. 1). From the results of the cell proliferation assay, we selected 5-FU as the best chemotherapeutic agent for combination with NK4 gene therapy and examined the assays using 5-FU thereafter. Furthermore, this method indicated that treatment with $10 \mu \mathrm{M}$ of 5-FU actually resulted in a significant, time-dependent growth inhibition of HuCC-T1 cells.

mRNA expression levels of TYMS, TYMP and DPYD were slightly altered. When considering the additive effect of NK4 gene expression in combination with 5-FU on cell growth,
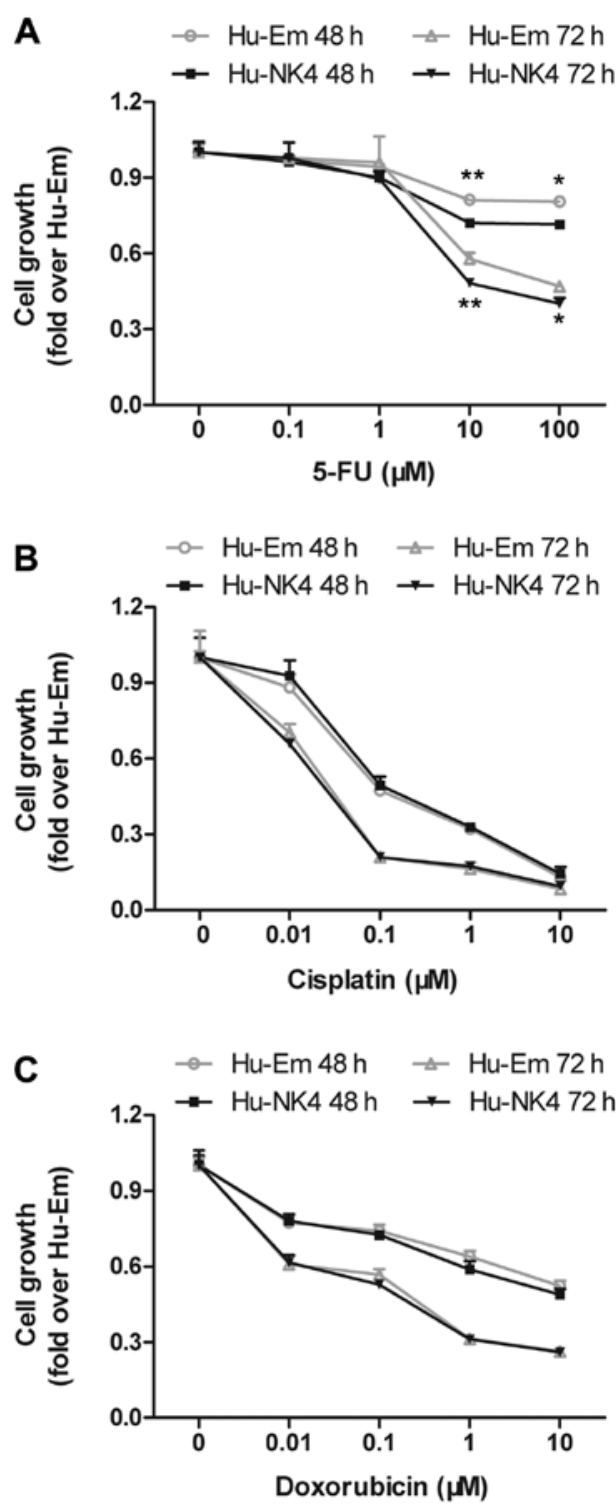

Figure 1. Effects of NK4 gene expression on CCA cell proliferation in vitro. $\mathrm{Hu}-\mathrm{NK} 4$ and $\mathrm{Hu}-\mathrm{Em}$ cells were incubated with 5-FU, cisplatin and doxorubicin. Over the time period of 48 and $72 \mathrm{~h}$ following treatment, the viability of the cells was assessed by MTT assay. (A) 5-FU, (B) cisplatin, (C) doxorubicin. Values shown are the means \pm SE from 3 independent experiments. The value in $\mathrm{Hu}-\mathrm{Em}$ cells at $0 \mu \mathrm{M}$ 5-FU was set as a control. The value in the control cells was set to 1.0 and the values in other cells were expressed as the fold over control $\left({ }^{*} \mathrm{P}<0.05,{ }^{* *} \mathrm{P}<0.01\right)$.

we hypothesized that NK4 gene expression influences 5-FU metabolism. Therefore, we assessed the expression of the metabolic enzymes of 5-FU. The mRNA levels of TYMS (encoding TS), TYMP (encoding TP) and DPYD (encoding DPD) tended to be slightly decreased in Hu-NK4 cells, but the gene expression levels were not significantly different from that in the Hu-Em cell line (Fig. 2).

NK4 overexpression enhances 5-FU-induced apoptosis of $\mathrm{HuCC}-\mathrm{Tl}$ cells. Since NK4 overexpression enhanced cell sensitivity to 5-FU, we investigated its role in mediating the 5-FU-response. We examined whether apoptosis is involved in the cytotoxic effect induced by the combination of NK4 gene expression and 5-FU. Flow cytometric analysis showed that 
A

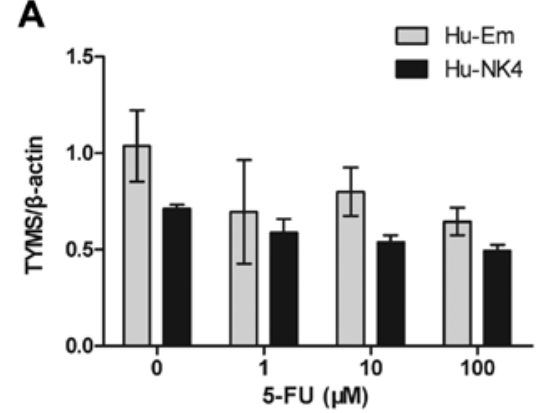

B

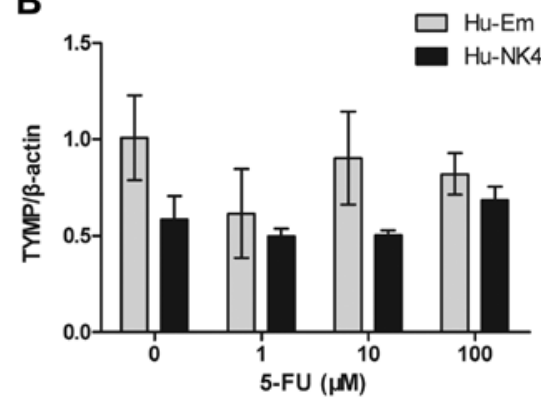

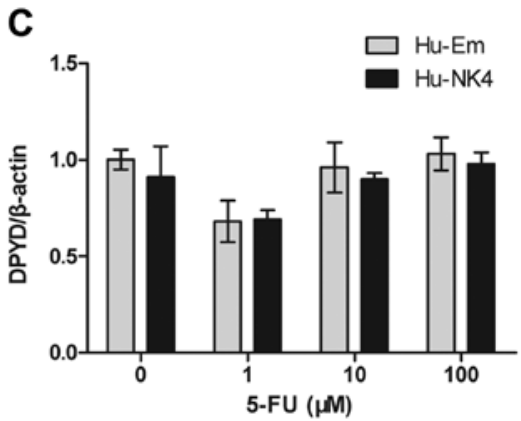

Figure 2. mRNA expression of (A) TYMS, (B) TYMP and (C) DPYD in CCA-transfected cell lines Hu-NK4 and Hu-Em as determined by RT-PCR. Each level of mRNA expression was normalized to $\beta$-actin mRNA. Values are expressed as the means $\pm \mathrm{SE}$ from 3 separate experiments.

A
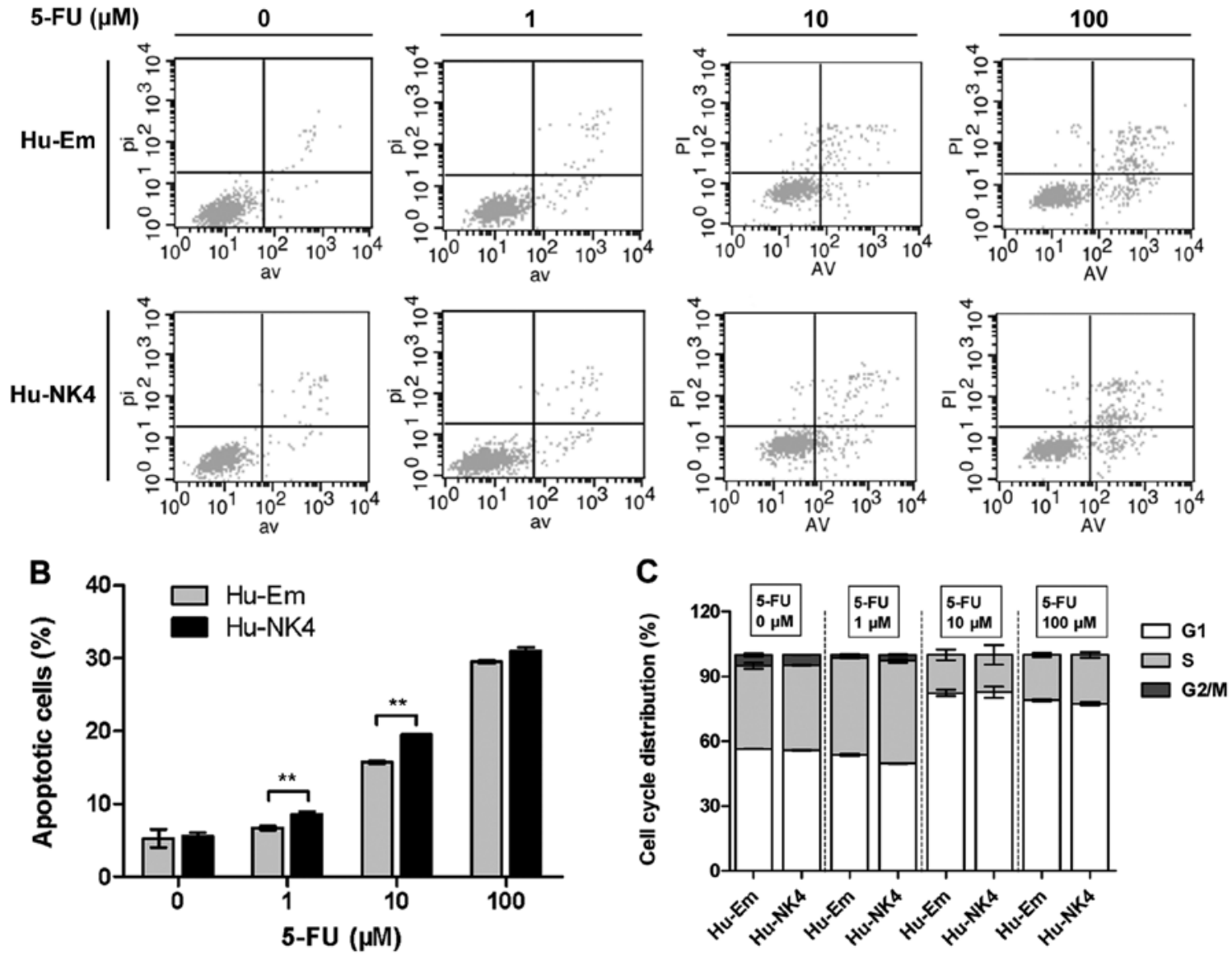

Figure 3. Flow cytometric analysis for quantification of apoptotic cells and cell cycle analysis. (A and B) Hu-NK4 and Hu-Em cells were treated with different concentrations of 5-FU, and the proportions of apoptotic cells were determined with flow cytometry. (C) Hu-NK4 and Hu-Em cells were stained with PI for DNA content after treatment for $24 \mathrm{~h}$ with 5-FU. DNA content was analyzed using flow cytometry. Bar graphs show the cell cycle phase distribution. Values are expressed as mean $\pm \mathrm{SE}$ from 3 separate experiments $\left.{ }^{* *} \mathrm{P}<0.01\right)$.

5-FU at concentrations of 1 and $10 \mathrm{M}$ increased the proportion of cells undergoing apoptosis at $48 \mathrm{~h}$; Hu-NK4 cells were affected to a greater extent than Hu-Em cells (Fig. 3A and B).

5 -FU acts as a cytostatic agent by arresting cells in the $\mathrm{G} 2$ phase $(21,22)$. Therefore, we performed cell cycle analysis following treatment with 5-FU for $24 \mathrm{~h}$ to analyze cell cycle distribution of these transfectants. The proportion of cells in the $\mathrm{G} 2 / \mathrm{M}$ phase of the cell cycle decreased after $1 \mu \mathrm{M} 5$-FU treatment, and even disappeared when the concentration was increased to 10 and $100 \mu \mathrm{M}$. Higher concentrations of 5-FU mainly caused arrest in the G1 phase and depletion of S phase. There were no significant differences between $\mathrm{Hu}-\mathrm{Em}$ and Hu-NK4 cells, suggesting that NK4 did not affect cell cycle distribution (Fig. 3C). 


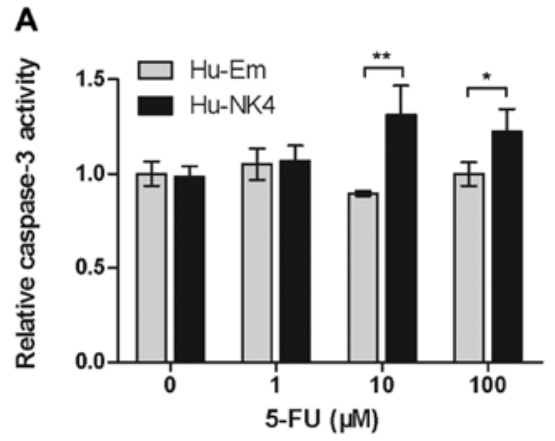

C

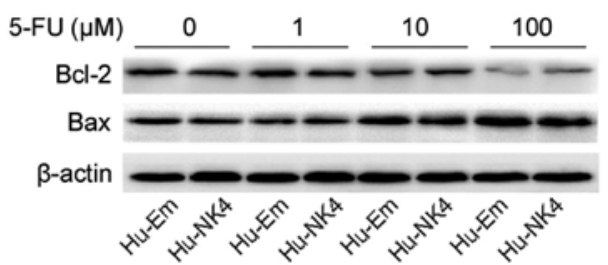

E

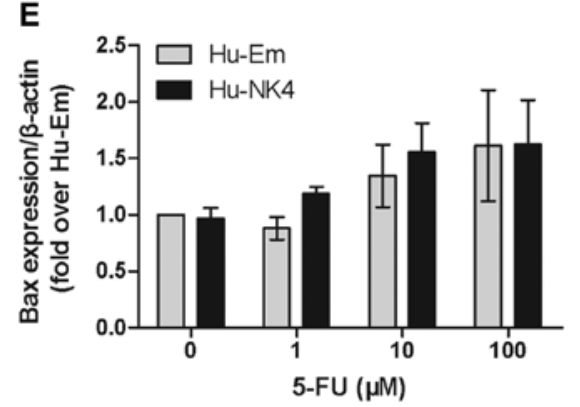

B

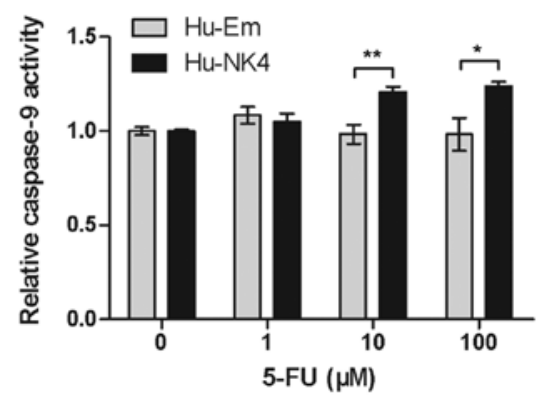

D

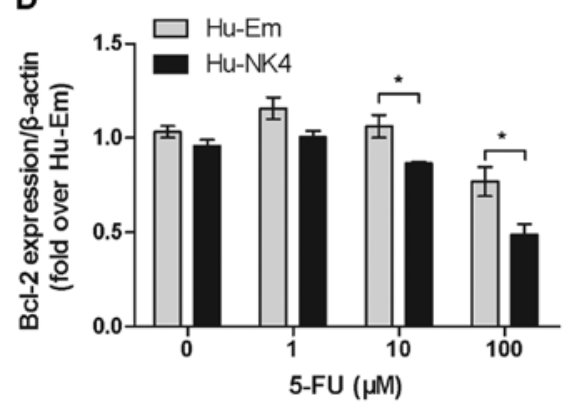

$\mathbf{F}$

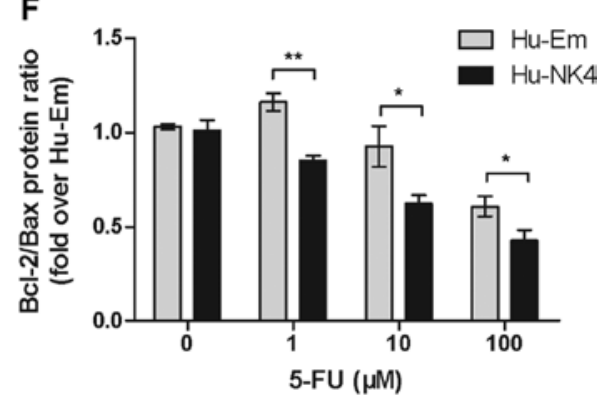

Figure 4. NK4 enhances 5-FU-induced apoptosis through the intrinsic pathway. (A and B) Effect of NK4 gene expression on 5-FU-induced caspase activity. Hu-NK4 and Hu-Em cells were treated with different concentrations of 5-FU for $48 \mathrm{~h}$, the cell lysates were assayed for in vitro caspase-3 and -9 activity. The released fluorescent products were measured. Data are expressed as means \pm SE of 3 independent experiments. (C-F) Effects of NK4 gene on the expression of the Bcl-2 family. Each cell line was treated with 5-FU at indicated concentrations for $48 \mathrm{~h}$. Protein levels of Bcl-2, Bax and $\beta$-actin were detected using western blotting. Values expressed as mean $\pm \mathrm{SE}$ from 3 independent experiments $\left({ }^{*} \mathrm{P}<0.05,{ }^{* *} \mathrm{P}<0.01\right)$.

NK4 augments 5-FU-induced apoptosis through the intrinsic pathway. We measured the activity of caspase-3 and caspase- 9 , the critical mediators of apoptosis, by colorimetric assay. 5-FU-induced activation of caspase- 3 and caspase-9, except at $1 \mu \mathrm{M} 5-\mathrm{FU}$, was significantly reduced in the Hu-NK4 cells (Fig. 4A and B). We further investigated the role of the intrinsic apoptotic pathway in 5-FU resistance. The pro-apoptotic Bcl-2 family members, Bcl-2 and Bax, are important initiators of mitochondrial-mediated apoptosis. Western blot analysis revealed that 5-FU dose-dependently downregulating $\mathrm{Bcl}-2$ and upregulating Bax expression (Fig. 4C-F). Bcl-2 expression following the different treatments (except at $1 \mu \mathrm{M}$ ) was higher in Hu-Em cells than that in Hu-NK4 cells. Significant difference in the Bcl-2/Bax ratio, but not in Bax, was observed between the two groups. These results further suggest a role for NK4 in regulating the 5-FU-induced intrinsic apoptotic pathway.

NK4 affects inhibition of HGF/Met signaling independent of 5-FU. We analyzed 5-FU-induced changes in the expres- sion levels of phosphorylated Met (p-Met) protein relative to an untreated, time-matched control. Western blot analysis demonstrated that phosphorylated Met was downregulated in response to treatment with $10 \mu \mathrm{M} 5-\mathrm{FU}$ at $48 \mathrm{~h}$ in both Hu-Em and Hu-NK4 cells. The level in the Hu-NK4 cells was decreased similarly when compared to Hu-Em cells, suggesting that 5-FU had little effect on the HGF/Met pathway. In our previous study, we demonstrated that the NK4 gene inhibits HGF-induced activation of Met. To clarify the functional role of HGF-induced activation of Met and 5-FU-induced deactivation, we investigated HGF in our study. Western blot analysis indicated that p-Met expression levels were increased in the HGF stimulation group, which was inhibited by NK4 transfectant and 5-FU treatment, and c-Met was strongly inhibited in the Hu-NK4 cell group, while there was no significant difference between the HGF stimulation group and HGF and 5-FU co-treatment group (Fig. 5). The result revealed that both NK4 and 5-FU were inhibitors of HGF-induced phosphorylation of Met, but they may be independent factors. 

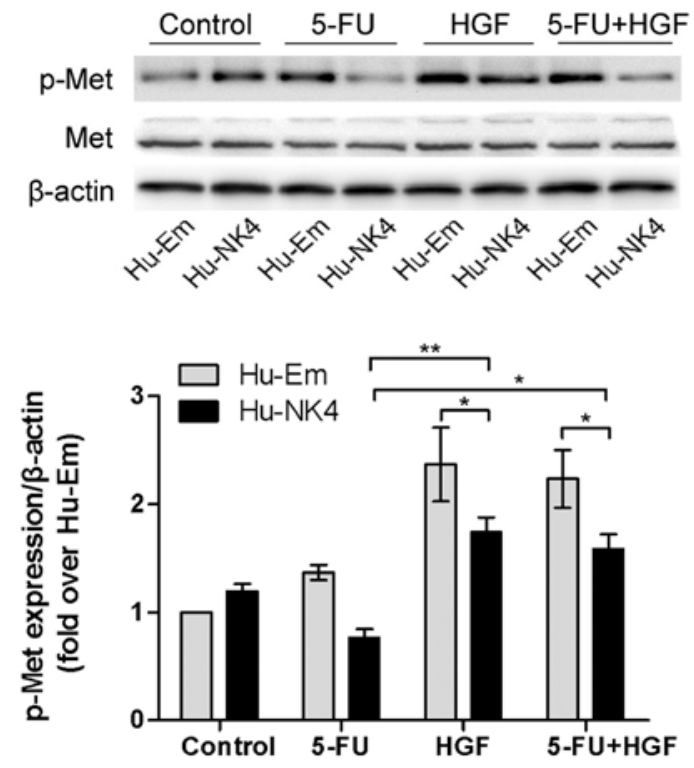

Figure 5. NK4 affects inhibition of HGF/Met signaling independent of 5-FU. The expression of total and phosphorylated forms of Met (p-Met) was assessed in $\mathrm{Hu}-\mathrm{NK} 4$ and $\mathrm{Hu}-\mathrm{Em}$ cells. Densitometric analysis was used and the band densities are shown as ratios of the objective band density/ $\beta$-actin density. Values are represented as means \pm SE from 3 independent experiments. The value in the control cells was set to 1.0 , and the values for the other cells were expressed as the fold over that in Hu-Em cells $\left({ }^{*} \mathrm{P}<0.05\right.$, *** $\mathrm{P}<0.01)$.

\section{Discussion}

In the present study, we demonstrated that the combination of NK4 gene therapy with chemotherapeutic agents, particularly 5-FU, enhanced the growth inhibition of HuCC-T1 cells. When we assessed the mechanism involved, 5-FU was found to exert an additional effect on apoptosis through the intrinsic pathway. The association between NK4 and 5-FU prompted us to further investigate the role of the intrinsic intracellular signaling of the $\mathrm{HGF} / \mathrm{Met}$ pathway. NK4 gene expression alone exerts potent antitumor activity by downregulating the HGF-induced phosphorylation of Met. 5-FU was another $\mathrm{HGF} / \mathrm{Met}$ signaling inhibitor independent of NK4. The influence of NK4 gene expression on enzymes involved in 5-FU metabolism was not elucidated.

Although 5-FU is the most common chemotherapeutic drug used in the treatment of CCA, evidence of 5-FU resistance has been reported both in in vitro studies using human CCA cell lines (23) and in vivo in CCA patients (24). Previous studies have demonstrated that the development of resistance of cancers to 5-FU may involve mechanisms including alterations in the exon of several genes including thymidylate synthase (TS) (16), thymidine phosphorylase (TP) (17) and dihydropyrimidine dehydrogenase (DPD) (25). In the present study, when cells were treated with 5-FU, the mRNA levels of TYMS (encoding TS), TYMP (encoding TP) and DPYD (encoding DPD) tended to be slightly decreased in the Hu-NK4 cells, while the gene expression level was not significantly different when compared to the Hu-Em cell line, consistent with previous reports of 5-FU-resistant CCA cell lines (26).

We next investigated the apoptosis of HuCC-T1 cells induced by the combination of 5-FU and NK4 gene expression from various aspects. The increase in the cell apoptosis rate evaluated by flow cytometry confirmed that NK4 gene expression enhances the cell apoptosis induced by 5-FU. The results prompted us to further investigate the apoptotic pathway involved in 5-FU resistance. Control of the intrinsic pathway is known to be governed by the Bcl-2 family members, and dysregulation of Bcl-2 family members are a common occurrence in tumorigenesis. Anti-apoptotic family members contain 4 Bcl-2 homology (BH) domains (BH1-4) and include Bcl-2, Bcl-XL, Mcl-1 and A1 (27). The pro-apoptotic molecule Bax normally resides in the cytoplasm and translocates to the mitochondria following an apoptotic stimulus. Loss of Bax expression has been shown to decrease sensitivity to chemotherapies in vitro (28) and enhance tumorigenesis in vivo (29). Preclinical models have clearly demonstrated a role for Bcl-2 family members in regulating the response to anticancer strategies. Furthermore, the ratio of $\mathrm{Bcl}-2$ to Bax protein appears to determine the susceptibility of cells to apoptotic stimuli $(30,31)$.

Activation of Bax and Bak results in the formation of pores in the mitochondrial membrane that allow pro-apoptotic molecules such as cytochrome $c$, Smac and Omi to be released into the cytosol. Cytochrome $c$ together with apoptotic proteaseactivating factor-1 (APAF-1), procaspase-9 and ATP form the apoptosome, a complex that results in the cleavage and activation of caspase-9, the initiator caspase for the intrinsic apoptotic pathway (32). Smac promotes apoptosis by binding to the IAP family of proteins (33). Binding of Smac to the IAPs de-represses IAP-mediated inhibition of caspases-3, -7 and -9 . When released from the mitochondria, Smac and Omi bind to members of the IAP family, alleviating IAP-induced caspase inhibition to promote apoptosis. In the direct activation model, anti-apoptotic members of the Bcl-2 family, Bcl-2, Bcl-XL and Mcl-1, inhibit binding of BH3-only molecules to $\mathrm{Bax} / \mathrm{Bak}$, thereby preventing their activation.

In the present study, 5-FU induced the activation of caspase- 3 and caspase-9. Bcl-2 expression was dose-dependently downregulated by $5-\mathrm{FU}$; the level in $\mathrm{Hu}-\mathrm{NK} 4$ cells decreased to a greater extend compared to that in the Hu-Em cells. Bax is an important initiator of mitochondrial-mediated apoptosis. It was upregulated by 5-FU; a significant difference in the Bcl-2/Bax ratio, but not in Bax, was observed between the two groups. These results confirm that the Bcl-2 family and the intrinsic apoptotic pathway are major effectors of 5-FU-induced apoptosis.

Having identified that 5-FU sensitivity was modified by $\mathrm{NK} 4$, we aimed to ascertain whether it affected the HGF/ Met signaling pathway. The difference in the level of p-Met between $\mathrm{Hu}-\mathrm{NK} 4$ and $\mathrm{Hu}-\mathrm{Em}$ cells was thought to be due to NK4 gene expression as the difference was observed even at $0 \mu \mathrm{M}$ of 5-FU. In addition, 5-FU at $10 \mu \mathrm{M}$ suppressed the phosphorylation of Met in both transfectants, indicating that 5-FU also has a suppressive effect on the the phosphorylation of Met, but there was no significant difference between the HGF stimulation group and HGF and the 5-FU co-treatment group. Therefore, we demonstrated that NK4 and 5-FU are two independent inhibitors of the $\mathrm{HGF} / \mathrm{Met}$ signaling pathway.

In conclusion, this study identified a novel role for NK4 as a modulator of 5-FU-induced death in CCA cells through activation of the intrinsic apoptotic pathway. 


\section{Acknowledgements}

We are grateful to Professor Toshikazu Nakamura and Professor Kiyomasa Oka (Osaka University Medical School, Japan) for their precious gift of the human NK4 expression plasmid pcDNA3/NK4. We acknowledge the guidance of Professor Zhining Fan, Dr Faming Zhang and Dr Yun Wang (The Second Affiliated Hospital of Nanjing Medical University, China) and we also appreciate the excellent technical assistance of Dr Yanggang Yuan and Dr Chenbo Ji (Institute of Pediatrics, Nanjing Medical University, China).This study was supported by grants from the Scientific Research Foundation for Health of Jiangsu Province (no. H200835) and Science and Technology Development Foundation of Nanjing Medical University (2012NJMU228).

\section{References}

1. Marsh Rde W, Alonzo M, Bajaj S, et al: Comprehensive review of the diagnosis and treatment of biliary tract cancer 2012. Part I: diagnosis-clinical staging and pathology. J Surg Oncol 106 332-338, 2012.

2. Blechacz B, Komuta M, Roskams T and Gores GJ: Clinical diagnosis and staging of cholangiocarcinoma. Nat Rev Gastroenterol Hepatol 8: 512-522, 2011.

3. Romiti A, D'Antonio C, Zullo A, et al: Chemotherapy for the biliary tract cancers: moving toward improved survival time. J Gastrointest Cancer 43: 396-404, 2012.

4. Nakamura T, Nishizawa T, Hagiya M, et al: Molecular cloning and expression of human hepatocyte growth factor. Nature 342: 440-443, 1989.

5. Date K, Matsumoto K, Shimura H, Tanaka M and Nakamura T: $\mathrm{HGF} / \mathrm{NK} 4$ is a specific antagonist for pleiotrophic actions of hepatocyte growth factor. FEBS Lett 420: 1-6, 1997.

6. Comoglio PM, Giordano S and Trusolino L: Drug development of MET inhibitors: targeting oncogene addiction and expedience. Nat Rev Drug Discov 7: 504-516, 2008.

7. Sattler M and Salgia R: The MET axis as a therapeutic target. Update Cancer Ther 3: 109-118, 2009.

8. Engelman JA, Zejnullahu K, Mitsudomi T, et al: MET amplification leads to gefitinib resistance in lung cancer by activating ERBB3 signaling. Science 316: 1039-1043, 2007.

9. Ohuchida K, Mizumoto K, Murakami M, et al: Radiation to stromal fibroblasts increases invasiveness of pancreatic cancer cells through tumor-stromal interactions. Cancer Res 64: 3215-3222, 2004.

10. Yano S, Wang W, Li Q, et al: Hepatocyte growth factor induces gefitinib resistance of lung adenocarcinoma with epidermal growth factor receptor-activating mutations. Cancer Res 68 9479-9487, 2008.

11. Onimaru M, Ohuchida K, Egami T, et al: Gemcitabine synergistically enhances the effect of adenovirus gene therapy through activation of the CMV promoter in pancreatic cancer cells. Cancer Gene Ther 17: 541-549, 2010.

12. Taiyoh H, Kubota T, Fujiwara H, et al: NK4 gene expression enhances 5-fluorouracil-induced apoptosis of murine colon cancer cells. Anticancer Res 31: 2217-2224, 2011.

13. Crea F, Nobili S, Paolicchi E, et al: Epigenetics and chemoresistance in colorectal cancer: an opportunity for treatment tailoring and novel therapeutic strategies. Drug Resist Updat 14: 280-296, 2011.

14. Banerjee D, Mayer-Kuckuk P, Capiaux G, Budak-Alpdogan T, Gorlick R and Bertino JR: Novel aspects of resistance to drugs targeted to dihydrofolate reductase and thymidylate synthase. Biochim Biophys Acta 1587: 164-173, 2002.
15. Longley DB, Allen WL and Johnston PG: Drug resistance, predictive markers and pharmacogenomics in colorectal cancer. Biochim Biophys Acta 1766: 184-196, 2006.

16. Leichman CG, Lenz HJ, Leichman L, et al: Quantitation of intratumoral thymidylate synthase expression predicts for disseminated colorectal cancer response and resistance to protracted-infusion fluorouracil and weekly leucovorin. J Clin Oncol 15: 3223-3229, 1997.

17. Metzger R, Danenberg K, Leichman CG, et al: High basal level gene expression of thymidine phosphorylase (platelet-derived endothelial cell growth factor) in colorectal tumors is associated with nonresponse to 5-fluorouracil. Clin Cancer Res 4: 2371-2376, 1998

18. Nishi M, Shimada M, Utsunomiya T, et al: Role of dihydropyrimidine dehydrogenase and thymidylate synthase expression in immunohistochemistry of intrahepatic cholangiocarcinoma. Hepatol Res 41: 64-70, 2011.

19. Morine Y, Shimada M, Utsunomiya T, et al: Role of thymidylate synthase and dihydropyrimidine dehydrogenase mRNA in intrahepatic cholangiocarcinoma. Surg Today 42: 135-140, 2012.

20. Wilson TR, Johnston PG and Longley DB: Anti-apoptotic mechanisms of drug resistance in cancer. Curr Cancer Drug Targets 9: 307-319, 2009.

21. Huang L, Wong YP, Cai YJ, Lung I, Leung CS and Burd A: Low-dose 5-fluorouracil induces cell cycle G2 arrest and apoptosis in keloid fibroblasts. Br J Dermatol 163: 1181-1185, 2010.

22. Okamoto S, Sakai M, Uchida J and Saito H: 5-Fluorouracil induces apoptotic cell death with $\mathrm{G} 2$ phase arrest in human breast cancer grafted in nude mice. Anticancer Res 16: 2699-2704, 1996.

23. Naus PJ, Henson R, Bleeker G, Wehbe H, Meng F and Patel T: Tannic acid synergizes the cytotoxicity of chemotherapeutic drugs in human cholangiocarcinoma by modulating drug efflux pathways. J Hepatol 46: 222-229, 2007.

24. Ikeguchi $M$, Hirooka $Y$, Makino $M$ and Kaibara $N$ : Dihydropyrimidine dehydrogenase activity of cancerous and non-cancerous tissues in liver and large intestine. Oncol Rep 8: 621-625, 2001.

25. Salonga D, Danenberg KD, Johnson M, et al: Colorectal tumors responding to 5-fluorouracil have low gene expression levels of dihydropyrimidine dehydrogenase, thymidylate synthase, and thymidine phosphorylase. Clin Cancer Res 6: 1322-1327, 2000.

26. Namwat N, Amimanan P, Loilome W, et al: Characterization of 5-fluorouracil-resistant cholangiocarcinoma cell lines. Chemotherapy 54: 343-351, 2008.

27. Danial NN: BCL-2 family proteins: critical checkpoints of apoptotic cell death. Clin Cancer Res 13: 7254-7263, 2007.

28. Zhang L, Yu J, Park BH, Kinzler KW and Vogelstein B: Role of BAX in the apoptotic response to anticancer agents. Science 290: 989-992, 2000.

29. Heiser D, Labi V, Erlacher M and Villunger A: The Bcl-2 protein family and its role in the development of neoplastic disease. Exp Gerontol 39: 1125-1135, 2004.

30. Oltvai ZN, Milliman CL and Korsmeyer SJ: Bcl-2 heterodimerizes in vivo with a conserved homolog, Bax, that accelerates programmed cell death. Cell 74: 609-619, 1993.

31. Yin XM, Oltvai ZN and Korsmeyer SJ: BH1 and BH2 domains of Bcl-2 are required for inhibition of apoptosis and heterodimerization with Bax. Nature 369: 321-323, 1994.

32. Zou H, Li Y, Liu X and Wang X: An APAF-1.cytochrome c multimeric complex is a functional apoptosome that activates procaspase-9. J Biol Chem 274: 11549-11556, 1999.

33. Nachmias B, Ashhab Y and Ben-Yehuda D: The inhibitor of apoptosis protein family (IAPs): an emerging therapeutic target in cancer. Semin Cancer Biol 14: 231-243, 2004. 